\title{
Kronik Böbrek Yetmezliği Nedeni ile Diyaliz Yapılan Çocuklarda Helikobakter Pilori Enfeksiyonu
}

\author{
Helicobacter Pylori Infection in Children on Dialysis Because of \\ Chronic Renal Failure
}

\author{
Gürkan Genç, Gönül Çaltepe*, Ozan Özkaya, Hülya Nalçacıoğlu, Murat Hökelek** , Ayhan Gazi Kalaycı * \\ Ondokuz Mayıs Üniversitesi Tıp Fakültesi, Pediatrik Nefroloji Bilim Dalı, Samsun, Türkiye \\ *Ondokuz Mayıs Üniversitesi Tıp Fakültesi, Pediatrik Gastroenteroloji Bilim Dalı, Samsun, Türkiye \\ **Ondokuz Mayıs Üniversitesi Tıp Fakültesi, Tıbbi Mikrobiyoloji Anabilim Dalı, Samsun, Türkiye
}

\section{Özet}

Amaç: Bu çalışmada, kronik böbrek yetmezlikli çocuk hastalarda gastrointestinal semptomlar ile Helicobacter pilori (HP) enfeksiyonu sıklığınının araştırılması planlanmıştır.

Yöntem: Çalışmaya kronik böbrek yetmezlikli 33 hasta ile yaş ve cinsiyeti aynı olan sağlıkı kontroller dahil edildi. Hastaların demografik, serolojik ve endoskopik bulguları incelendi ve gastrointestinal sistem semptomları sorgulandı. Çalışmaya dahil edilen tüm hasta ve kontrol grubundan serumda HP-ıgG düzeyi çalışıldı.

Bulgular: Yirmi yedi periton diyalizi, altı hemodiyaliz hastası çalışmaya dahil edildi. HP seropozitifliği hasta grubunda \%51.5, kontrol grubunda \%60.6 olarak tespit edildi $(p=0.46)$. Yirmi hastaya özefagogastroduodenoskopi uygulandı ve hastaların \%30'unda dokuda HP tespit edildi. Dispepsi tüm hastaların \%42.2'sinde belirlendi. Dispeptik hastaların \%57.1'inde HP seropozitifliği, \%36.4'ünde dokuda HP tespit edildi. Pozitif serolojisi olan hastaların \%60'ında dokuda HP gösterilirken, seronegatif olan sadece bir olguda dokuda HP tespit edildi.

Sonuç: Toplumumuzda sık görülen ve kolonizasyonu çocukluk yaşlarında başlayan HP enfeksiyonu, çalışmamızda da serolojik olarak hem hasta hem de kontrol grubunda yüksek bulunmuştur. Her biri transplantasyon adayı olan bu hastalar için asemptomatik olsa bile enfeksiyonun saptanması ve tedavisi önem taşımaktadır. (Haseki Tıp Bülteni 2013; 51: 1-4)

Anahtar Kelimeler: Helicobakter pylori, çocuk, diyaliz

\section{Giriş}

Kronik böbrek yetmezlikli hastaların birçoğunda üremiye bağlı çeşitli gastrointestinal belirtiler görülmektedir. Sıkça gözlenen kusma ve dispeptik yakınmalar iştah kaybına, yetersiz kalori alımına sebep olmakta ve çocuklarda büyüme ve gelişmeyi olumsuz etkilemektedir $(1,2)$.

\section{Abstract}

Aim: We aimed to investigate the frequency of gastrointestinal symptoms and Helicobacter pylori (HP) infection in children with chronic renal failure.

Methods: The study involved 33 patients with end-stage renal disease and 33 age- and sex-matched healthy controls. Serological, endoscopic and demographic features of the patients were determined and gastrointestinal symptoms were questioned. HP IgG levels were evaluated in all patients and controls.

Results: Twenty-seven peritoneal dialysis and 6 hemodialysis patients were included in the study. The HP seropositivity was $51.5 \%$ and $60.6 \%$ in uremic children and normal controls, respectively $(p=0.46)$. Twenty patients underwent esophagogastroduodenoscopy and HP was detected in $30 \%$ of them. Dyspepsia was observed in $42.4 \%$ of all patients. In patients with dyspepsia, HP seropositivity rate was $57.1 \%$ and biopsy proven HP was $36.4 \%$. Biopsy proven HP was determined in $60 \%$ of patients with positive serology and in one with negative serology.

Conclusion: HP infection, which is common in our population and begins in early childhood, is found to be frequent in both patient and healthy groups. Even if asymptomatic, it is very important to determine and treat this infection, in these patients who are potential transplant candidates. (The Medical Bulletin of Haseki 2013; 51: 1-4)

Key Words: Helicobacter Pylori, child, dialysis

Gram negatif, spiral, flagelli bir basil olan Helikobakter pilori (HP)'nin kolonizasyonu erken çocukluk çağında başlar ve inflamasyona neden olur. Çoğu asemptomatik olsa da bu inflamasyon gastrit, gastro-duodenal ülser ve hatta gastrik kansere neden olabilmektedir. Üremik hastalarda, çeşitli ve çok sayıda ilaç kullanma zorunluluğu, mide boşalma zamanında uzama ve serum gastrin düzeyinde artış gibi nedenlerle 
dispeptik yakınmalar sık görülmekte, HP enfeksiyonunun da eklenmesi ile bu yakınmaların sıkığı artmaktadır (2-8).

Bu çalışmada, son dönem böbrek yetmezliği nedeni ile diyaliz programında izlenen çocuk hastalarda HP enfeksiyonunun sıkığı ve klinik öneminin araştııılması amaçlanmışıtı.

\section{Gereç ve Yöntem}

Bu çalışmaya Ondokuz Mayıs Üniversitesi Tıp Fakültesi'nde takip edilen 33 kronik böbrek yetmezliği hastası ve polikliniğe kontrol amacı ile başvuran, herhangi bir böbrek veya gastrointestinal rahatsızlığ//hastalığı olmayan, benzer cinsiyet ve yaş grubunda 33 kontrol olgusu dahil edilmiştir. Hasta ve kontrol grubunda son iki ayda antibiyotik ve $\mathrm{H} 2$-reseptör inhibitör tedavisi alma hikayesi olanlar çalışmaya dahil edilmedi. Çalışmaya yerel etik kurul onayı alındıktan sonra başlandı.

Hastaların yaş, cinsiyet, vücut ağırlıkları, vücut kitle indeksleri, hemoglobin, albümin düzeyleri, aldıkları ilaçlar ve günlük hap sayıları, takip süreleri, diyalize giren hastaların diyaliz tipleri ve süreleri, Kt/V oranları, tüm olguların epigastrik dolgunluk, ağrı, şişkinlik, erken doyma, retrosternal yanma hissi, ağza acı su gelme gibi dispepsi semptomları sorgulandı. Üst gastrointestinal endoskopi yapılan hastaların antrumdan alınan mukozal biyopsi sonuçları kaydedildi. Ailelerden onam alındıktan sonra tüm hastalar ve kontrol grubundan ELISA ile serum HP-lgG düzeyleri çalışıldı.

Elde edilen veriler SPSS sürüm 15.0 kullanılarak değerlendirildi. Parametreler ortalama \pm standart sapma (minimum-maksimum değerler) olarak verildi. Normal dağıııma uyan veriler student $t$ testi, uymayan veriler Mann-Whitney $U$ testi ile değerlendirildi. $P<0.05$ değerinden düşük sonuçlar istatistiksel olarak anlamlı kabul edildi.

\section{Bulgular}

Çalışmaya alınan kronik böbrek yetmezlikli hastaların 27'si periton diyalizi (PD) ile, altısı hemodiyaliz (HD) ile takip ediliyordu. Periton diyalizi ile izlenen hastaların yaş ortalaması 12.62 \pm 4.84 (3-18) iken, hemodiyaliz ile izlenen hastaların yaş ortalaması 16.16 \pm 1.16 (14-17) idi. Periton diyalizi ve HD programında izlenen hasta grupları arasında demografik özellikler ve laboratuar bulguları açııından fark gözlenmedi (Tablo 1). Hastaların 17'sinde (\%51.5) HP-IgG antikoru pozitif saptandı. Aynı yaş grubundan alınan ve hiçbir şikayeti olmayan 33 olguda HP-lgG seropozitifliği 20 (\%60.6) olguda belirlendi. Hasta ve kontrol grubu arasında HP-IgG pozitifliği açısından istatistiksel olarak anlamlı fark bulunmadı $(P=0.46)$.

Tablo 1. Hastaların demografik özellikleri

\begin{tabular}{lccc}
\hline & Periton Diyalizi ( $\mathbf{n = 2 7})$ & Hemodiyaliz (n=6) & P değeri \\
\hline Yaş (yıl) & $12.62 \pm 4.84(3-18)$ & $16.16 \pm 1.16(14-17)$ & 0.211 \\
Cinsiyet (e/k) & $11 / 16$ & $3 / 3$ & 0.683 \\
Böbrek yetmezlĭgi tanı sonrası takip süresi (yll) & $5.7 \pm 3.78$ & $5.33 \pm 2.87$ & 0.982 \\
Diyaliz takip süresi & $3.98 \pm 2.38$ & $2.83 \pm 0.75$ & 0.324 \\
Kan üre nitrojen düzeyi (mg/dl) & $62.9 \pm 9.73$ & $6.77 \pm 8.98$ & 0.627 \\
Kan kreatinin düzeyi (mg/dl) & $7.78 \pm 1.86$ & $6.92 \pm 0.96$ & 0.285 \\
Vücut kitle indeksi & $17.01 \pm 4.17$ & $17.5 \pm 1.47$ & 0.781 \\
Kt/V oranları & $2.43 \pm 0.6$ & $1,58 \pm 0,06$ & 0,01 \\
Hemoglobin düzeyi (mg/dl) & $9.58 \pm 1.3$ & $9.22 \pm 0.2$ & 0.599 \\
Albumin düzeyi (mg)dl) & $3.62 \pm 0.38$ & $3.6 \pm 0.34$ & 0.949 \\
Günlük alınan hap sayısı & $18.62 \pm 4.06$ & $20.5 \pm 3.41$ & 0.396 \\
Dispeptik semptomlar & $10(\% 37)$ & $4(\% 66.7)$ & 0.184 \\
HP-lgG pozitifliği & $12(\% 44.4)$ & $5(\% 83.3)$ & 0.085
\end{tabular}

Tablo 2. Endoskopi yapılan hastaların sonuçları

\begin{tabular}{|c|c|c|c|c|c|c|c|}
\hline \multirow[t]{2}{*}{ Enoskopi Bulguları } & \multicolumn{3}{|c|}{$\begin{array}{c}\text { Periton Diyalizi } \\
\text { Hp Seroloji }\end{array}$} & \multicolumn{3}{|c|}{$\begin{array}{l}\text { Hemodiyaliz } \\
\text { Hp Seroloji }\end{array}$} & \multirow[t]{2}{*}{ Toplam } \\
\hline & $n=17$ & + & - & $n=3$ & + & - & \\
\hline Duodenit & 2 & 1 & 1 & 3 & 2 & 1 & 5 \\
\hline Gastrit & 8 & 5 & 3 & 1 & 0 & 1 & 9 \\
\hline Gastrik ülser & 0 & & & 1 & 1 & 0 & 1 \\
\hline Doğal & 7 & & & 0 & & & 7 \\
\hline
\end{tabular}


Transplantasyon hazırlığı yapılan, ailelerinden onay alınabilen ve uygulamayı tolere edebilen üçü HD 17'si PD olmak üzere 20 hastaya endoskopi yapıldı, gastrit $(n=9)$, duodenit $(n=5)$, ülser $(n=1)$ gibi bulgular saptandı (Tablo 2 ). Endoskopi yapılan hastaların 11'inde dispeptik yakınmalar vardı, bunların da sekizinde (\%72.7) endoskopide patolojik bulgular saptandı, dördünde (\%36.4) HP hem serolojik olarak hem de dokuda gösterildi. Endoskopide patoloji saptanan hastaların sekizinde (\%61.5) dokuda HP tespit edildi, biri serolojik olarak negatifti.

Hastaların \%42.4'ünde $(n=14)$ dispeptik yakınmalar saptandı, bunların yedisinde (\%50) HP seropozitifliği saptanırken, yakınmaları olmayan 19 hastanın dokuzunda (\%47) HP seropozitifliği saptandı. Endoskopi yapılan asemptomatik dokuz hastanın beşinde (\%55) patolojik bulguya rastlandı, üçünde (\%33.3) HP pozitifliği saptandı. HP IgG seropozitifliği olan 17 hastanın 10'una endoskopi yapılmıştı. Bunların altısında (\%60) dokuda HP gösterildi. Bir hastada HP-lgG antikoru negatif iken dokuda HP saptandı.

\section{Tartışma}

Helikobakter pilori enfeksiyonu çocukluk döneminde kazanılmakta ve sıklığı yaşla artmaktadır. Tanısında altın standart her ne kadar gastrik biyopsi materyalinde mikroorganizmanın gösterilmesi ve kültürde üretilmesi olsa da, non-invazif olması nedeniyle, C14 üre nefes testi, gaitada HP antijeni ve geniş kesimlerde tarama amacıyla serolojik testlerden de yararlanılmaktadır (9-11).

Literatürde diyaliz ile izlenen hastalarda HP enfeksiyonu sıklığı ile ilgili çeşitli ve çelişkili raporlar bulunmaktadır, çalışma metodları farklı olmakla beraber \%17-80 gibi geniş bir aralıkta rapor edilmiştir (12-16). HP enfeksiyonunun, diyaliz hastalarında düşük oranlarda görüldüğü çalışmalar mevcutken, kontrol grubuna göre eşit ya da yüksek olarak sonuçlanan çalışmalar da bulunmaktadır (17-21).

Khazaei ve ark. (22) çocuk üremik hastalarda yaptığı çalışmada hasta grubunda enfeksiyon sıklığı \%66.7 iken, kontrol grubunda \%20 olarak gösterilmiştir. Aynı çalışmada asemptomatik hastaların \%75'inde, semptomatik hastaların \%62.5'inde HP saptandığı bildirilmiştir. Hemodiyaliz ile izlenilen 4-16 yaş arası 31 çocuk hastada yapılan bir çalışmada, biyopsi materyalinde HP pozitifliği \%64.5 olarak rapor edilmiştir (23). Dört yüz erişkin diyaliz hastasında yapılan bir çalışmada, Sugimoto ve ark. (24) HP prevalansını normal popülasyonun altında ve ortalama \%41.8 olarak tespit etmişlerdir. Hooman ve ark. 117 son dönem böbrek yetmezlikli çocuk hastada yaptıkları çalışmada HP pozitiflik oranını \%24 olarak belirlemişlerdir (25). HP enfeksiyon sıklığı düşük bulunan çalışmalarda bu düşüklük, diyaliz hastalarında sık kullanılan antibiyotiklere ve kronik böbrek hastalarının yeterli antikor yanıtı oluşturamamasına bağlanmıştır $(17,20,26)$. Ülkemizden yapılan çalışmalarda çocukluk yaş grubunda HP seropozitifliği oranı \%19.6 ile \%50 arasında değişen sıklıklarda bildirilmiştir $(27,28)$. Bununla birlikte, çalışmamızda seropozitiflik oranı hasta grubunda \%51.5 iken sağlıklı kontrol grubunda \%60.6 olarak belirlenmiş ve seropozitiflik açısından istatistiksel olarak anlamlı fark saptanmamıştır $(p=0.46)$.

Dispepsi, gastrointestinal hastalıklar açısından önemli bir bulgudur. Son dönem böbrek yetmezlikli 24 çocuk olgunun gastrointestinal bulgularının değerlendirildiği bir çalışmada, bu bulgunun üremik çocuk hastalarda çok güvenilir olmadığı, asemptomatik hastaların üçte birinde endoskopik anormallik olduğu belirlenmiştir (22). Aynı çalışmada HP enfeksiyonu sıklığı semptomatik hastalarda \%62.5, asemptomatik hastalarda \%75 olarak belirlenmiştir. Emir ve ark. (2) çocuk son dönem böbrek yetmezlikli hastalarda yaptıkları çalışmada semptomatik hastaların \%80'inde, asemptomatik hastaların \%22.7'sinde anormal endoskopik bulgulara rastlamışlardır. Bizim çalışmamızda, dispeptik hastalar ile asemptomatik hastalar arasında endoskopik bulgular açısından bir fark yoktu. Asemptomatik hastaların da \%40'ında patolojik endoskopi bulgularına rastlandı. Çalışmamızdaki bulgular ve literatürdeki çelişkili sonuçlar ışı̆̆ında dispeptik semptomların bu hasta grubunda güvenilirliğinin yüksek olmadığı, bu konuda daha geniş hasta gruplarında çalışmanın tekrarlanması gerektiği düşünülmüştür.

HP enfeksiyonu ve son dönem böbrek yetmezliği ile ilgili yapılan çalışmalarda bazı yazarlar asemptomatik vakalarda rutin serolojik taramanın gerekli olmadığını söylese de, erişkin hastalarda yapılan bazı çalışmalarda, bizim vakalarımızda olduğu gibi asemptomatik üremik hastalarda da gastrointestinal lezyonların sık görüldüğü bildirilmiştir (29-32). Erişkin hemodiyaliz hastalarında yapılan bir çalışmada, dokuda HP pozitifliği \%63 olarak bildirilirken, anormal endoskopi bulguları olan hastaların \%85.7'sinde HP tespit edilmiştir (32). Emir ve ark. (2) 37 hastanın 17'sinde (\%46) gastrointestinal lezyonlar tespit etmiş, mukozal değişiklikleri olan bu hastaların \%62.5'inde dokuda HP pozitifliğini göstermişlerdir. Bizim çalışmamızda da, anormal endoskopi bulguları saptanan hastaların 7'sinde (\%53.8) dokuda HP pozitifliği saptandı.

Üremik çocuk hastalardaki endoskopik lezyonlar açısından hastalar değerlendirildiğinde, Emir ve ark. bu hasta grubunda mukozal lezyonların ülseratif lezyonlardan daha sık gözlendiğini bildirmişlerdir (2). Khazaei ve ark. (22) da çocuk üremik hastalarda yaptıkları bir çalışmada mukozal lezyonları daha sıklıkla belirlemişlerdir. Bizim çalışmamızda da literatür ile uyumlu olarak mukozal lezyonlar ülseratif lezyonlara göre daha sık gözlenmiştir.

Sonuç olarak, HP enfeksiyonu ülkemizde çocukluk yaş grubunda sık olarak gözlenmektedir. Çoğu asemptomatik olan bu enfeksiyon, sağlıklı çocuklardan daha farklı olarak her biri transplantasyon adayı olan üremik hastalarda risk 
oluşturmaktadır ve morbiditeyi artıırmaktadır. Ayrıca, çocuk hastalarda dispeptik yakınmalar olmasa bile hem serolojik hem de morfolojik olarak HP sıklı̆ının yüksek olduğu gösterilmiştir. Bu da, transplantasyon adayı olan bu hastaların asemptomatik olsa bile HP için en azından serolojik tarama yapılmasının önemini ortaya koymaktadır. HP enfeksiyonunun üremik hastalarda sık görüldüğü, ancak dispepsi ile hem HP pozitifliği hem de endoskopik lezyonlar arasında net bir ilişki olmadığı sonucuna varımıştır. Bu konuda çocukluk yaş grubunda yapılacak daha geniş kapsamlı çalışmalara ihtiyaç vardır.

Araştırma Ondokuz Mayıs Üniversitesi Tıp Fakültesi Bilimsel Araştırmaları Destekleme Fonu tarafından desteklendi (PYO.TIP.1901.09.023).

\section{Kaynaklar}

1. Ravelli AM, Ledermann SE, Bisset WM, Trompeter RS, Barratt TM, Milla PJ. Foregut motor function in chronic renal failure. Arch Dis Child 1992;67:1343-7.

2. Emir S, Bereket G, Boyacioğlu S, Varan B, Tunali H, Haberal M. Gastroduodenal lesions and Helicobacter pylori in children with end-stage renal disease. Pediatr Nephrol 2000;14:837-40.

3. Davenport A, Shallcross TM, Crabtree JE, Davison AM, Will EJ, Heatley RV. Prevalence of Helicobacter pylori in patients with end-stage renal failure and renal transplant recipients. Nephron 1991;59:597-601.

4. Tsukada K, Miyazaki T, Katoh H, et al. Helicobacter pylori infection in hemodialysis patients. Hepatogastroenterology 2003;50:2255-8.

5. Wee A, Kang JY, Ho MS, Choong HL, Wu AY, Sutherland IH. Gastroduodenal mucosa in uraemia: endoscopic and histological correlation and prevalence of Helicobacter-like organisms. Gut 1990;31:1093-6.

6. Hopkins RJ, Girardi LS, Turney EA. Relationship between Helicobacter pylorieradication and reduced duodenal and gastric ulcer recurrence: a review. Gastroenterology 1996;110:1244-52.

7. Misiewicz JJ. Current insights in the pathogenesis of Helicobacter pylori infection. Eur J Gastroenterol Hepatol 1995:7:701-3.

8. Uemura N, Okamoto S, Yamamoto S, et al. Helicobacter pylori infection and the development gastric cancer. N Engl J Med 2001;345:784-9.

9. Suerbaum S, Michetti P. Helicobacter Pylori infection. N Engl J Med 2002;347:1175-86.

10. Xia HH, Kalantar JS, Wyatt JM, et al. High sensitivity and specificity of a laboratory-based serological test, pylori DTect ELISA, for detection of Helicobacter Pylori infection. Diagn Microbiol Infect Dis 2000;36:69-74.

11. Xia HH, Wong BC, Wong WM, et al. Optimal serological tests for detection of Helicobacter Pylori infection in the Chinese population. Aliment Pharmacol Ther 2002;16:521-6.

12. Davenport A, Shallcross TM, Crabtree JE, Davison AM, Will EJ, Heatley RV. Prevalence of Helicobacter pylori in patients with end-stage renal failure and renal transplant recipients. Nephron 1991;59:597-601.
13. Wee A, Kang JY, Ho MS, Choong HL, Wu AY, Sutherland IH. Gastroduodenal mucosa in uraemia: endoscopic and histological correlation and prevalence of Helicobacter-like organisms. Gut 1990;31:1093-6.

14. Simenhoff ML, Saukkonen JJ, Burke JF, Wesson LG Jr, Schaedler RW, Gordon SJ. Bacterial populations of the small intestine in uremia. Nephron 1978;22:63-8.

15. Tsukada K, Miyazaki T, Katoh H, et al. Helicobacter pylori infection in hemodialysis patients. Hepatogastroenterology 2003;50:2255-8.

16. Muñoz De Bustillo E, Sánchez Tomero JA, Sanz JC, et al. Eradication and follow-up of Helicobacter pylori infection in hemodialysis patients. Nephron 1998;79:55-60.

17. Shousha S, Arnaout AH, Abbas SH, Parkins RA. Antral Helicobacter Pylori in patients with chronic renal failure. J Clin Pathol 1990;43:397-9.

18. Jaspersen $D$, Fassbinder $W$, Heinkele $P$, et al. Significantly lower prevalence of Helicobacter Pyloriin uremic patients than in patients with normal renal function. J Gastroenterol 1995;30:585-8.

19. Nakajima F, Sakaguchi M, Amemoto K, et al. Helicobacter Pylori in patients receiving long-term dialysis. Am J Nephrol 2002;22:468-72.

20. De Vecchi AF, QuattriniM, Boni $F$, et al. Epidemiology of Helicobacter Pylori in dialysis patients. Perit Dial Int 1995;15:178-9.

21. Khedmat H, Ahmadzad-Asl M, Amini M, et al. Gastro-duodenal lesions and Helicobacter pyloriinfection in uremic patients and renal transplant recipients. Transplant Proc 2007;39:1003-7.

22. Khazaei MR, Imanieh MH, Hosseini Al-Hashemi G. Gastrointestinal evaluation in pediatric kidney transplantation candidates. Iran J Kidney Dis 2008;2:40-5.

23. Mortazavi F, Rafeey M. Endoscopic findings and Helicobacter pylori in children on long-term hemodialysis. Pak J Biol Sci 2008;11:1840-3.

24. Sugimoto M, Sakai K, Kita M, Imanishi J, Yamaoka Y. Prevalence of Helicobacter pylori infection in long-term hemodialysis patients. Kidney Int 2009;75:96-103.

25. Hooman N, Mehrazma M, Talachian E, Otukesh H, Nakhaii S. Helicobacter pylori infection in pediatric candidates for kidney transplantation. Iran J Kidney Dis 2011;5:124-9.

26. Descamps-Latscha B. Immune system in end stage renal disease. Curr Opin Nephrol Hypertens 1993;2:883-91.

27. Söğüt A, Acun C, Cavuldak Ş, Komşu Z, Tomaç N. Zonguldak ilinde 6 ay-15 yaş grubu çocuklarda Helicobacter pylori seropozitifliği ve risk etmenlerinin incelenmesi. Türk Pediatri Arşivi 2004;39:152-7.

28. Göral V, Özdal B, Kaplan A, Sııt D, Danış R. Diyarbakır ilinde Helikobakter pilori antikor prevalansı. Akademik Gastroenteroloji Dergisi 2006;5:47-50.

29. Knoll G, Cockfield S, Blydt-Hansen T, et al. Kidney Trasplant Working Group of the Canadian Society of Transplantation. Canadian Society of Transplantation: consensus guidelines on eligibility for kidney transplantation. CMAJ 2005;173:S1-25.

30. Sariko S, Rautelin H, Kyllönen L, et al. Should Helicobacter Pylori be treated before kidney transplantation? Nephrol Dial Transplant 2001;16:2053-7.

31. Schoonjans R, Van VB, Vandamme W, et al. Dyspepsia and gastroparesis in chronic renal failure: the role of Helicobacter pylori. Clin Nephrol 2002;57:201-7.

32. Al-Mueilo SH. Gastroduodenal lesions and Helicobacter pylori infection in hemodialysis patients. Saudi Med J 2004;25:1010-4. 